\title{
IJTARP
}

Intemational Joumal of Transactional Analysis

Research \& Practice

10 (2), $87-100$

https://doi.org/10.29044/v10i2p87

\section{UK Council for Psychotherapy Position Statement on NICE Guideline for Depression in Adults}

(C) 2019 The Signatories

\section{Editor's Note}

The following is reproduced here, with permission of the UK Council for Psychotherapy and their collaborators, because it makes interesting and generally applicable points about research methodologies.

The references are:

UKCP (2019) https://www.psychotherapy.org.uk/wp-content/uploads/2019/07/NICE-Depression-coalitionposition-statement.pdf accessed 16 October 2019

UKCP (2019)

https://cdn.ymaws.com/www.psychotherapyresearch.org/resource/resmgr/docs/downloads/StakeholderPositionSt atement.pdf accessed 16 October 2019 


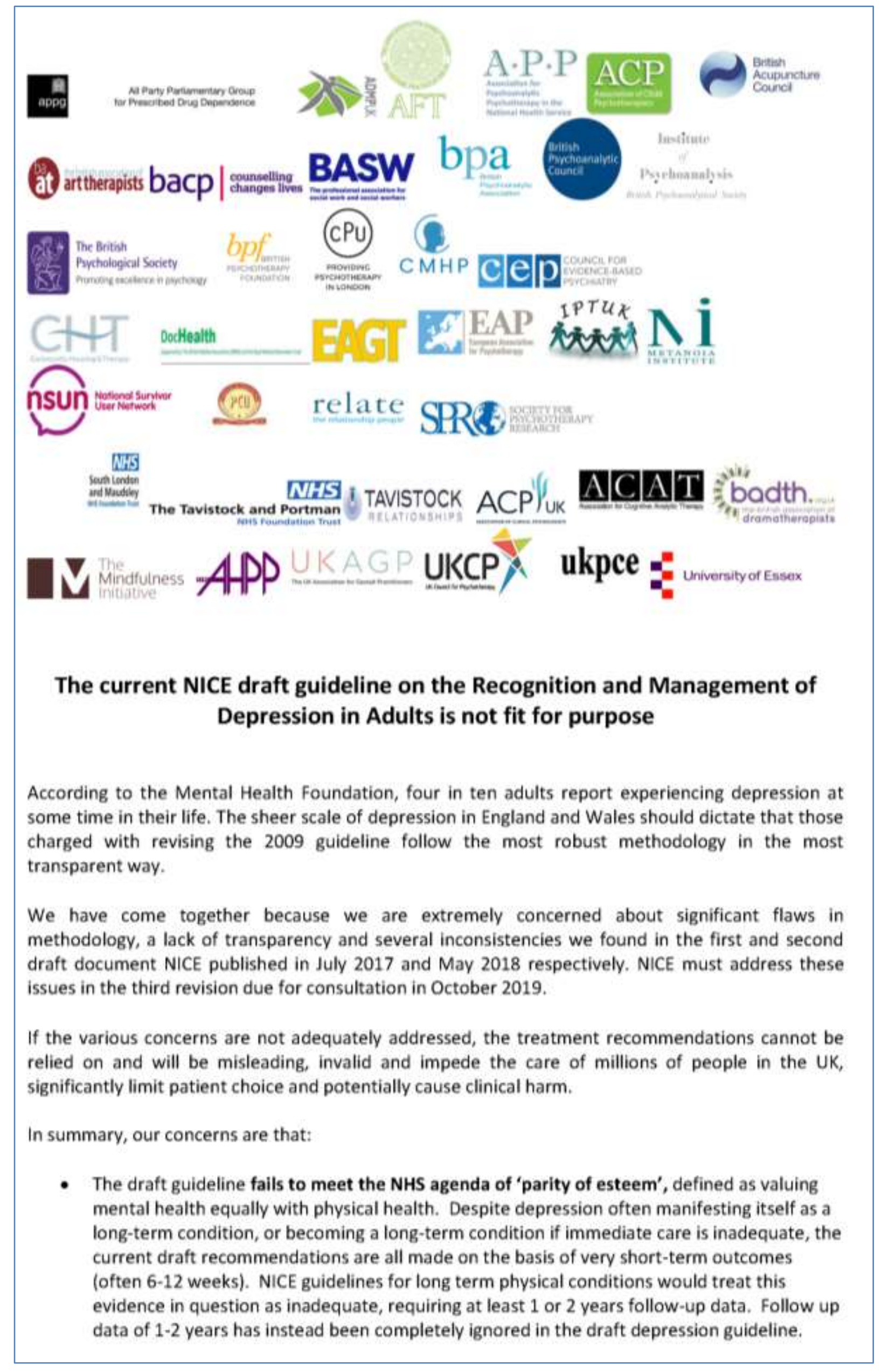


- Ensuring that the views and experiences of those who use the services are properly taken account of, should be the sine qua non of a publicly funded body tasked with devising clinical guidelines, particularly as these services are fundamentally shaped by the guidance NICE produces. The current draft guideline has used out-of-date evidence of service user experiences mostly dating back to before 2004 and has failed even to incorporate this evidence into treatment recommendations.

- The current draft guideline is completely out of step with US and European guideline methodologies. The Guideline Committee has created its own method for categorising depression by longevity and severity - leading to erroneous and unhelpful classification of research studies which do not match clinical, service user experiences or research outcomes.

- The current draft guideline has used inadequate methods for working out whether a treatment has shown itself to be effective within a research study-ignoring the severity of depression at the start of the treatment. Much better methods exist for this and are widely used in the research community.

- The current draft guideline used statistical analyses (network meta-analyses) that are associated with serious and unique risks. These were inadequately reported and addressed (leading to violations of statistical assumptions in the approach adopted) and this therefore puts the resulting treatment recommendations into serious question.

- The current draft guideline has an extremely narrow focus on symptom outcomes and fails to take into account other aspects of service user experience which have long been called for such as quality of life, relationships and ability to participate in work, education or society.

- The current draft guideline poses a serious threat to patient choice and will result treatments being offered which may not have the best chance of relieving their suffering (which in turn will contribute to poor cost effectiveness in the long term).

Our position, therefore, is that a full and proper revision of the guideline must take place allowing sufficient time to properly address the concerns listed in this statement. These amendments must be made before the guideline is published.

\section{Document Prepared by (and correspondence to):}

Dr Felicitas Rost: felicitas.rost@gmail.com

Dr Susan McPherson: smcpher@essex.ac.uk

See full position statement here: https://www.psychotherapyresearch.org/news/452957/SPR-UKStakeholder-Campaign-against-the-NICE-draft-Guidelines-for-Depression-in-Adults.htm

\section{Organisational signatories:}

All-Party Parliamentary Group for Prescribed Drug Dependence: Rt Hon Sir Oliver Letwin MP, Chair Association for Dance Movement Psychotherapy UK (ADMP UK): Jackie Edwards, Chair Association for Family Therapy and Systemic Practice (AFT): Dr Reenee Singh, CEO Association for Psychoanalytic Psychotherapy in the NHS (APP): Andrew Soutter, Chair Association of Child Psychotherapists (ACP): Isobel Pick, Chair

British Acupuncture Council: Robert Strange OBE, CEO

British Association of Art Therapists (BAAT): Dr Val Huet (PhD), CEO

British Association for Counselling and Psychotherapy (BACP): Dr Andrew Reeves, Chair 
British Association of Social Workers: Dr Ruth Allen, CEO

British Psychoanalytic Association (BPA): Dr David Simpson, President

British Psychoanalytic Council (BPC): Gary Fereday, CEO

British Psychoanalytic Society (and Institute of Psychoanalysis): Catalina Bronstein, President

British Psychological Society (BPS): Sarb Bajwa, CEO

British Psychotherapy Foundation (BPF): Mike Owen, CEO

Camden Psychotherapy Unit (CPU): Ora Dresner, CEO

College of Mental Health Pharmacy (CMHP): Juliet Shepherd, President

Community Housing and Therapy (CHT): Dr Peter Cockersell, CEO

Council for Evidence-based Psychiatry (CEP): Dr James Davies, co-founder

Dochealth: Dr Antony Garelick, Director

European Association for Psychotherapy (EAP): Charles Cassar, President

European Association for Gestalt Therapy (EAGT): Beatrix Wimmer, President

Interpersonal Psychotherapy UK (IPT-UK): Yvonne Hemmings, Chair

Metanoia Institute: Professor Sheila Owen-Jones, CEO

National Survivor User Network (NSUN): Sarah Yiannoullou, Managing Director

Psychotherapy and Counselling Union (PCU): Richard Bagnall-Oakeley, Chair

Psychotherapy Foundation: Dr Stephen Buller, Chair

Relate: Aidan Jones, CEO

Society for Psychotherapy Research UK (SPR UK): Dr Felicitas Rost (PhD), President

South London and Maudsley NHS Foundation Trust (SLAM): Dr Matthew Patrick, CEO

Tavistock and Portman NHS Foundation Trust: Paul Jenkins, CEO

Tavistock Relationships: Andrew Balfour, CEO

The Association of Clinical Psychologists UK (ACP-UK): Dr Che Rosebert

The Association for Cognitive Analytic Therapy (ACAT): Dr Alison Jenaway, Chair

The British Association of Dramatherapists (BADth), Madeline Andersen-Warren, Acting Chair

The Mindfulness Initiative: Jamie Bristow, Director

UK Association for Gestalt Practitioners (UKAGP): Dr Belinda Harris, Chair

UK Association for Humanistic Psychology Practitioners (UKAHPP): John Fletcher, Chair

UK Council for Psychotherapy (UKCP): Professor Sarah Niblock, CEO

UK Person-Centred Experiential (UKPCE): Dr David Murphy, Convenor

University of Essex (UoE): Dr Susan McPherson, Senior Lecturer, School of Health and Social Care 


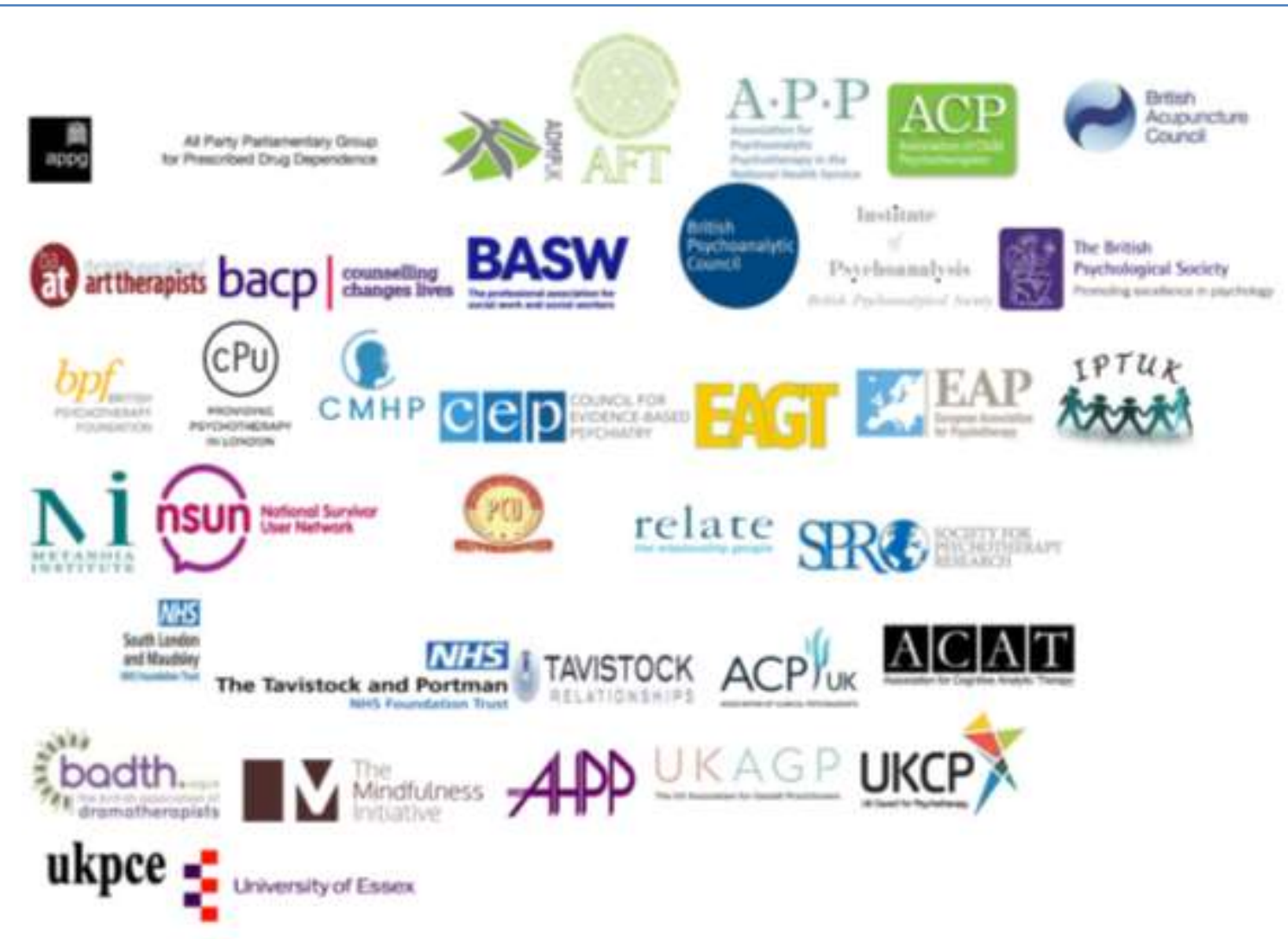

\section{Stakeholder position statement on the NICE guideline for depression in adults}

\section{Organisational signatories}

All-Party Parliamentary Group for Prescribed Drug Dependence: Rt Hon Sir Oliver Letwin MP, Chair Association for Dance Movement Psychotherapy UK (ADMP UK): Jackie Edwards, Chair Association for Family Therapy and Systemic Practice (AFT): Dr Reenee Singh, CEO Association for Psychoanalytic Psychotherapy in the NHS (APP): Andrew Soutter, Chair Association of Child Psychotherapists (ACP): Isobel Pick, Chair British Acupuncture Council: Robert Strange OBE, CEO British Association of Art Therapists (BAAT): Dr Val Huet (PhD), CEO British Association for Counselling and Psychotherapy (BACP); Dr Andrew Reeves, Chair British Association of Social Workers: Dr Ruth Allen, CEO British Psychoanalytic Council (BPC): Gary Fereday, CEO British Psychoanalytic Society (and Institute of Psychoanalysis): Catalina Bronstein, President British Psychological Society (BPS): Sarb Bajwa, CEO British Psychotherapy Foundation (BPF): Mike Owen, CEO Camden Psychotherapy Unit (CPU): Ora Dresner, CEO College of Mental Health Pharmacy (CMHP): Juliet Shepherd, President Council for Evidence-based Psychiatry (CEP); Dr James Davies, co-founder European Association for Psychotherapy (EAP): Charles Cassar, President European Association for Gestalt Therapy (EAGT): Beatrix Wimmer, President Interpersonal Psychotherapy UK (IPT-UK): Yvonne Hemmings, Chair Metanoia Institute: Professor Sheila Owen-Jones, CEO National Survivor User Network (NSUN): Sarah Yiannoullou, Managing Director Psychotherapy and Counselling Union (PCU): Richard Bagnall-Oakeley, Chair Psychotherapy Foundation: Dr Stephen Buller, Chair Relate: Aidan Jones, CEO Society for Psychotherapy Research UK (SPR UK); Dr Felicitas Rost (PhD), President South London and Maudsley NHS Foundation Trust (SLAM): Dr Matthew Patrick, CEO Tavistock and Portman NHS Foundation Trust: Paul Jenkins, CEO 
Tavistock Relationships: Andrew Balfour, CEO

The Association of Clinical Psychologists UK (ACP-UK): Dr Che Rosebert

The Association for Cognitive Analytic Therapy (ACAT): Dr Alison Jenaway, Chair

The British Association of Dramatherapists (BADth), Madeline Andersen-Warren, Acting Chair

The Mindfulness Initiative: Jamie Bristow, Director

UK Association for Gestalt Practitioners (UKAGP): Dr Belinda Harris, Chair

UK Association for Humanistic Psychology Practitioners (UKAHPP): John Fletcher, Chair

UK Council for Psychotherapy (UKCP): Professor Sarah Niblock, CEO

UK Person-Centred Experiential (UKPCE): Dr David Murphy, Convenor

University of Essex (UoE): Dr Susan McPherson, Senior Lecturer, School of Health and Social Care

\section{Individual signatories}

Professor Sir Simon Wessely, Regius Chair of Psychiatry, King's College London; President, Royal Society of Medicine; Past President, Royal College of Psychiatrists.

Professor Clare Gerada, General Practitioner and Senior Partner Hurley Group; Medical Director, Practitioner Health Programme.

Jennifer Edwards CBE FFPH, Past Chief Executive Mental Health Foundation

Michael Barkham PhD, FBPsS; Professor of Clinical Psychology, University of Sheffield

Sharon Beirne, UKCP registered Gestalt psychotherapist

Vincent Beja, Research Committee of the European Association for Gestalt Therapy (EAGT)

Jon Blend, MA, Adult \& Child Psychotherapist

Heather Bolton, Registered Psychotherapist (GPTI, UKCP) \& Mindfulness Teacher (UK Network registered)

Dr Javier Malda Castillo, BPS Chartered Clinical Psychologist, North West Borough NHS Foundation Trust

Martin Capps, UKCP, MSC, SM GPTI, Gestalt Psychotherapist, Trainer and Supervisor

Zoë Chouliara, Professor in Mental Health, Abertay University

Richard Davis, Senior Lecturer counselling/psychotherapy, University of Central Lancashire

Lesley Dougan, Senior Lecturer, MA Counselling and Psychotherapy, Practice School of Nursing and Allied

Health, Liverpool John Moores University

Vienna Duff, Gestalt Psychotherapist, UKCP, UKAGP

Robert Elliott, PhD, Professor of Counselling, University of Strathclyde

Vicky Eugenio, MA Gestalt Psychotherapy- UKCP; Gestalt Centre-London

Ed Fellows, UKCP Gestalt Psychotherapist, EMDR, sensorimotor, MBCT \& Senior Counsellor, PTSD and

bereavement lead, Southwark IAPT

Jane Dianne Flint, UKCP registered Gestalt Psychotherapist

Dr Belinda Harris, Associate Professor, University of Nottingham, UKCP Registered Psychotherapist

Catherine Hayes Mbacp (Senior Acc), Assistant Professor of Counselling, University of Nottingham

Dr Michael Hengartner, Zurich University of Applied Sciences

Dr Trish Hobman, Subject Director, Counselling, Coaching and Mentoring, School of Psychological and Social Sciences, York St John University

Dr Jonathan Isserow, Head of Partnerships; Convenor, MA Art Psychotherapy, Dept of Psychology, University Of Roehampton

Stephen Joseph, PhD, Professor of Heaith and Social Care University of Nottingham

Prof Vicky Karkou, Professor of Arts and Wellbeing, Edge Hill University

Christine Kennett, Teaching and Supervising Member, Gestalt Psychotherapy \&Training Institute

Prof Willem Kuyken, Professor of Mindfulness and Psychological Science, University of Oxford

Patricia Hunt, President Elect of the European Association for Psychotherapy and International Officer of the

UK Council for Psychotherapy.

Michal Kostrzewski, Vice President of the PTPG

Lynne Lacock, Senior Lecturer/Course Lead, School of Psychological and Social Sciences York St John University

Prof Del Loewenthal, Emeritus Professor of Psychotherapy and Counselling, University of Roehampton

Roderic London, BACP \& UKCP Accredited Counsellor and Psychotherapist

Renata Mizerska, EC Member and External Relations \& NOGTs Officer of the EAGT, President of the PTPG

Dr Susan Mizen, Devon Partnership NHS Trust; Chair Talking Therapies Task Force

David Murphy, PhD, CPsychol, AFBPsS, Associate Professor, University of Nottingham

Dr Susie Orbach, Consultant, The Balint Consultancy

Dr Vanja Orlans, Director, Psychology Matters Ltd.

Dr Peter Pearce, Faculty Head, Applied Social and Organisation Sciences, Metanoia Institute 
Martin Pollecoff, Chair, UK Council for Psychotherapy

Sue Price, PhD, Assistant Professor of Counselling, University of Nottingham

Lynne Rigaud, Vice Chair of the Science and Research Committee of the European Association for

Psychotherapy

Margaret Rosemary, Gestalt Psychotherapist, GPTI and UKCP registered

Jan Roubal, MD PhD, Chair of the Research Committee of the European Association for Gestalt Therapy (EAGT)

Prof Andrew Samuels, Prof of Analytical Psychology, University of Essex; Former Chair UKCP

Dr Saima Siddique, Director of Counselling, Psychotherapy and Experiential Therapies, School of Education.

University of Aberdeen

Peter Schulthess, Chair of the Science and Research Committee of European Association for Psychotherapy

Dr David Taylor, Training Psychoanalyst, Institute of Psychoanalysis \& Visiting Professor, University College

London

Emma Tickle, Assistant Professor of Counselling University of Nottingham.

Helen Thomas, MA MSc UKCP Gestalt Psychotherapist

Graham Westwell, Senior Lecturer in Counselling and Psychotherapy, Edge Hill University.

Cătălin Zaharia, President of the European Association for Neuro Linguistic Psychotherapy

Document prepared by (and correspondence to):

Dr Felicitas Rost, President, Society for Psychotherapy Research UK

Email: felicitas, rost@gmail.com

Dr Susan McPherson, Senior Lecturer, School of Health and Social Care, University of Essex

Email: smcoher@essex.ac.uk

\section{Background}

According to the Mental Health Foundation, four in ten adults report experiencing depression at some time in their life. The sheer scale of depression in England and Wales should dictate that those charged with revising the 2009 guideline follow the most robust methodology in the most transparent way.

In November 2017, the signatories to this position statement wrote to David Haslam, Chair of the National Institute for Health and Care Excellence (NICE), to formally request a second stakeholder consultation of the next revision of the guideline on the Recognition and Management of Depression in Adults, prior to its formal publication. We did this because, along with many other stakeholders, we were extremely concerned about significant flaws in methodology, lack of transparency and several inconsistencies we found in the draft document published in July 2017.

We briefed a number of peers and MPs who took seriously our concerns that the document was not fit for purpose. In February 2018, an Early Day Motion was tabled and a number of MPs signed a cross-party letter to NICE asking that they respond to our letter. A meeting took place between the members of this stakeholder coalition and NICE in April 2018, following which, the NICE executive opened a second four-week consultation on the revised draft.

Update March 2019: in July 2018, thirty-four MPs and Peers including a former Minister for Health, wrote to Sir Andrew Dillon, CEO of NICE, asking NICE to address our concerns. In October 2018, registered stakeholders received notification that the new guideline would undergo a third revision starting in December 2018. The planned publication date for the guideline is February 2020 with a consultation period from 2 nd October to 13 th November.

The scope for the third revision does not include any of the concerns detailed in this statement. Instead, NICE proposes to update the existing evidence review and to indude new work on 'patient choice'. It is unclear what body of evidence 'patient choice' refers to, but NICE have specified that this does not refer to patient experience (of which there is a significant body of evidence). 


\section{Summary of Serious Concerns}

The various methodological concerns we raised in our first response to the draft have not been addressed in the revised version.

Thus, we maintain our position that this guideline is not fit for purpose and if published will seriously impede the care of millions of people in the UK suffering from depression, potentially even causing clinical harm.

Under NICE's own rules, a second consultation can occur exceptionally if "information or data that would significantly alter the guideline were omitted from the first draft, or evidence was misinterpreted in the first draft and the amended interpretation significantly alters the draft recommendations ${ }^{i 1}$. Both conditions have been met in this case. Stakeholders identified wide ranging and fundamental methodological flaws in the draft and offered recommendations for addressing these. In spite of acknowledging the serious omissions and misinterpretations through issuing a second consultation, these key issues have not been addressed in the new draft.

The quality assurance process in the stakeholder response document and in the overall process appear to fall short of acceptable scientific standards and lack scientific integrity. Our position, therefore, is that a full and proper revision of the guideline must take place allowing sufficient time for the guideline group to properly address the concerns listed in this statement. These issues relate both to the omission of large amounts of data as well as the potentially significant material impact on the recommendations that would arise from their inclusion. If these issues are not adequately addressed, the treatment recommendations cannot be relied on.

The draft guideline in its current form poses a serious threat to patient choice and will result in patients being offered a limited selection of treatments, which may not be the treatments that have the best chance of relieving their suffering (which in turn will contribute to poor cost effectiveness in the long term). The following amendments must be made before the guideline is published:

1. NICE should conduct a proper analysis of 1 and 2-year follow-up data from trials and prioritise treatment recommendations made on the basis of these data over and above recommendations which are made on the basis of short term outcomes (less than 1 year).

2. A full systematic review of primary studies of service user experience is required, employing formal methodology for qualitative synthesis; AND findings from such a review must be incorporated into the broader approach to quantitative review and treatment recommendations rather than being left as a stand-alone section.

3. Trials where the majority of the population is clinically complex, chronic or treatment resistant need to be grouped together as 'persistent depression' for the purposes of review, following the European Psychiatric Association².

4. The guideline review must look at the amount of clinical effect (e.g. partial recovery) from a severe baseline point and not ignore treatment effects because clients do not fully recover by the end of treatment. Moreover, categorisations of depression severity must be based on validated tools, not un-validated non-transparent functions of them.

5. Findings from indirect or mixed comparisons using Network Meta-Analysis (NMA) should only be used to supplement evidence derived from direct comparisons. NICE must reanalyse the data using standard meta-analyses and should NMA be used to supplement the findings a validated and reliable model for doing so should be employed.

6. NICE must run a reanalysis of studies using quality of life and/or functioning outcomes where these are available and prioritise recommendations based on these measures, given that these are the measures of greatest priority to service users. 
This position statement outlines in detail below the basis for each of these required amendments.

\section{Methodological focus of concerns}

This coalition of stakeholders is driven by and comes from a position of psychotherapeutic neutrality and scientific integrity, just as the development of the guideline should be. In other words, whilst some of the organisations involved may have a particular leaning towards one therapeutic approach or another, our concerns are directed towards the methodology adopted by the guideline development group and specifically their (a) selection, (b) grouping, and (c) analysis of the supporting evidence.

The evidence-based medicine paradigm has been shaped by medical science. This requires some adjustment when comparing and contrasting medical treatments with psychological treatments. The overall methodological approach in the guideline inherently favours (a) medical trials over psychological trials; and (b) particular psychological treatments over others. This is not an acceptable scientific stance and creates biases that are based on subjective choices rather than good scientific evidence of treatment effectiveness.

Moreover, we note that the guideline displays an over-reliance on one type of scientific method and fails to take account of the wide variety of good quality evidence available that uses a variety of methodologies and designs. Relying entirely on Randomized Controlled Trials (RCTs) represents a seriously restricted model of science. The various limitations of RCTs specifically in the field of mental health have been pointed out repeatedly by experts from many scientific disciplines and positions irrespective of therapeutic modality. Most psychotherapy trials are not sufficiently powered to detect true differences ${ }^{2}$, and guidelines that ignore important evidence as they occur in clinical practice are concerning. Thus, there is a need to take account of large standardised routine outcome datasets, such as the Improving Access to Psychological Therapies (IAPT) dataset.

As the Health Foundation and Cochrane Collaboration have stressed ${ }^{\text {t5 }}$, creating sound policy requires that we draw on a diverse range of evidence and that cohort studies as well as qualitative and case study research evidence maximizes the value of reviews to policy and practice decision. making. We recognise that some of these broader methodological matters should and will be addressed in our stakeholder responses to the NICE manual consultation currently ongoing. Nevertheless, serious methodological flaws in the current draft guideline for depression outlined below relate to the Guideline Committee's application of methodological practices set out in the current NICE manual.

\section{The guideline must enable NHS services to deliver 'parity of esteem'}

'Parity of esteem' refers to the legal requirement, set out in the Health and Social Care Act (2012). for NHS bodies to give equal priority to mental and physical health. Treatment recommendations set out in the draft guideline for depression will have a direct impact on the future commissioning of mental health care services and workforce planning (including IAPT and secondary care) and thus have an impact on the care of millions of people with depression and their families.

Depression often manifests as a long-term condition, or becomes a long-term condition if immediate care is inadequate. Depression can also be highly episodic and there is a high relapse rate. For example $38 \%$ of IAPT clients are repeat attenders ${ }^{6}$. It is imperative for research to demonstrate that treatment effects are long-lasting, or indeed to note where effects might appear over the long-term follow-up (sleeper effects). 
NICE states that "the aim of [an] intervention is to restore health through the relief of symptoms and restoration of function, and in the longer term, to prevent relapse". NICE guidelines for long-term physical conditions such as epilepsy and asthma examine treatment outcome data over 1-10 years. The evaluation of treatments for depression must meet the same standards as guidelines for long term physical conditions. This requires the guideline to base recommendations on evidence concerning the long-term effectiveness of treatments.

The current draft recommendations are all made on the basis of very short-term outcomes (often 6 12 weeks) and always less than 1 year. This is inadequate as a basis for recommendations for longterm conditions (whether physical or mental). NICE guidelines for long-term physical conditions would treat this evidence as inadequate, requiring at least 1 or 2 years follow-up data. Follow up data of 1-2 years have been omitted in the draft depression guideline.

The Guideline Committee state that there are insufficient studies with long term follow up data to conduct such analyses. If this is the case then it is inappropriate for the guideline to make any firm recommendations for specific treatments based on (albeit large amounts of) short-term outcome data. Large amounts of poor evidence must not be used in place of small amounts of good evidence. NICE should conduct a proper analysis of 1 and 2-year follow-up data where available and prioritise treatment recommendations made on the basis of this data over and above current recommendations made on the basis of short term outcomes (less than 1 year). This is likely to alter the recommendations significantly, since, for example, where follow-up data is available these tend to be favourable to longer-term therapies over short-term therapies.

\section{The guideline must review evidence on service user experience}

Ensuring that the views and experiences of those who use the services are properly taken account of, should be the sine qua non of a publicly funded body tasked with devising clinical guidelines, particularly as these services are fundamentally shaped by the guidance NICE produces.

While the guideline committee has consulted service users as part of the guideline development process, it has largely ignored the voices of service users, using out-of-date evidence of service user and carer experiences mostly dating back to before 2004 and has failed even to incorporate this evidence into treatment recommendations.

The decision not to update this section is not justified given that evidence relating to service user experience has at least equal value to quantitative evidence of clinical outcomes. In omitting such a significant body of evidence, NICE has failed to follow its own stated approach to Patient and Public Involvement (PPI), which "reflects policy initiatives to involve patients, service users, carers and the public across the NHS and social care." In setting out its approach to PPI, NICE refers to policy contained in the Health and Social Care Act 2012; the NHS Constitution; Putting People at the Heart of Care 2009; and Essential Standards of Quality and Safety.

These policies collectively enshrine the right of service users to be fully involved in decisions affecting their care. The specific role of NICE within the planning of healthcare is to commission or conduct methodologically robust systematic reviews of evidence and to use findings from such reviews to inform a set of guidelines for the delivery and implementation of care. PPI must reflect this specific role and hence guidelines must include methodologically rigorous reviews concerning service user experience. 
By not updating this section, the Buideline fails to reflect the dynamic context in which people experience depression which is intertwined with the social and economic context in which people live. There is growing evidence of the impact of austerity on depression and many clients have been significantly affected by reductions in their benefits, loss of work or changes to employment conditions resulting from the economic downturn and political choices. There have been changes which may impact on the extent to which clients encounter stigma. Moreover, recent policy changes, such as the Care Act 2014 and benefits changes, mean that carers' experiences are unlikely to be the same as in 2004 or 2009. These changes in context are further justification for ensuring up to date evidence is reviewed and included in this guideline now.

The service user section copied over from the 2009 guideline was itself inadequate. The overall approach was methodologically weak, unsystematic and lacking the level of transparency and rigour expected in qualitative synthesis approaches as referred to in the NICE manual. A scoping search was carried out in March 2018 by Dr Susan McPherson to identify qualitative peer reviewed research published between 2009 and 2018. This scoping found 93 studies that included over 2500 participant voices that were not considered. In addition, a further qualitative systematic review examines the experiences of relatives and carers of people with depression using formal qualitative synthesis methods?. This recent literature extends client experience data to many underrepresented groups (such as those listed in the scoping document as requiring 'special consideration'); and takes account of changes in socio-economic and cultural circumstances.

Given the purpose of a NICE review is to conduct methodologically sound reviews of evidence, a full systematic review of primary studies is required, employing formal methodology for synthesis such as meta-ethnographic synthesis, meta-synthesis or formal grounded theory as recommended in the NICE manual". This would enhance understanding of service user experiences, a position held by several bodies including the American Psychiatric Association, the Cochrane Collaboration" and the Health Foundation. Findings from such a review must also be incorporated into the broader approach to quantitative review and treatment recommendations rather than being left as a stand-alone section. Updating this review and taking account of its findings when forming treatment recommendations would have a significant impact on the recommendations because, for example, service users often voice a preference for more rather than less choice and for longer-term rather than shorter-term therapies, as alluded to in the 2009 service user experience section.

\section{Categorisation of persistent forms of depression must reflect good evidence}

The current draft guideline is out of step with US and European guideline methodologies, leading to erroneous and unhelpful classification of research studies which do not match clinical or service user experiences. The adopted distinction between treatment resistant and chronic depression (as well as distinguishing both from complex depression) is particularly concerning. There is no evidence that warrants these distinctions and no appropriate sensitivity analyses were carried out. These distinctions cause confounds in treatment research, as many participants in the trials meet the guideline's definition of treatment resistant and chronic depression and in some cases also complex depression.

Trials where the majority of the population is clinically complex, chronic or treatment resistant need to be grouped together as 'persistent depression' for the purposes of review, following the European Psychiatric Association ${ }^{10}$. This would have a significant impact on the guideline. In the future NICE also needs to look at whether the overall categorical system of mental disorders really fits with service user experience or whether a more trauma-focused approach would fit service user experience better. In the meantime, the current guideline must at least be in line with the best clinical and research evidence. 


\section{The guideline must use appropriate methods for determining treatment effect}

The current draft guideline has used inadequate methods for working out whether a trial has found a clinically significant treatment effect. The Guideline Committee devised a method for dichotomising study populations into 'More severe' or 'Less severe' in order to account for baseline severity when determining treatment effect. This approach has no scientific validity and overrides the categorisations of severity used by well-established measures as well as established methods of calculating the clinical significance of treatment effects. This dichotomy is also relied on for the Network Meta Analysis. Indeed the Guideline Committee admit that this dichotomisation was driven by their wish to conduct a Network Meta Analysis, which is an inappropriate form of reverse engineering, particularly as dichotomization inflates effect sizes ${ }^{11}$. The Guideline Committee claim that this dichotomization was supported by and will benefit General Practitioners but present no evidence or this claim.

This is of critical importance because persistent, severe and complex forms of depression represent a large component of the population of people with depression, yet there are very few treatments which have been found to help. Full remission from a severe baseline is difficult to achieve, whereas a treatment which helps some service users move from severe depression to mild or moderate depression (i.e. 'partial recovery'), for example, would be worth recommending. Service users with persistent depression are already doubly disadvantaged by their long-term mental illness because of the lack of parity of esteem reflected in the decision to omit long-term outcome data. In order to identify clinical practices which can relieve the severe and ongoing suffering within this population, the guideline review must look at the amount of clinical effect from a severe baseline point and not ignore treatment effects simply because clients do not fully recover by the end of treatment. Examining partial recovery is therefore critical in order to identify treatments which can be of some benefit to people with severe and/or complex depression.

\section{The guideline must not base its primary recommendations on results of Network Meta-Analysis}

The current draft guideline used statistical analyses (i.e. network meta-analysis, NMA) that are associated with serious and unique risks over and above that of standard meta-analyses that need careful addressing when employing it ${ }^{12,13,14}$. The Guideline Committee disagrees yet offers no scientific basis for their disagreement. NMA is an experimental technique with no formal expert consensus yet established on its appropriateness for this type of review. It relies on particular conditions, which, if not met, render the outcome unreliable. It is not the role of NICE to provide an experimental platform for methodological technicians. This type of methodology must first be subject to critical discussion and consensus forming within the scientific field through peer-reviewed publications and debate.

Use of the methodology in national guidelines should also be subject to formal stakeholder consultation, which has not yet taken place. NICE has over-reached its function in undertaking this experimental technique and making it the basis of a national guideline impacting on millions of people experiencing distress. This approach represents a serious deviation from accepted methodologies, is not supported by several experts in the field, has not been subject to a proper stakeholder consultation and should not be used.

The main assumption underpinning the validity of NMA is that the indirect and mixed comparisons are only valid when the studies included in the synthesis are similar in their distribution of effect modifiers ${ }^{15}$. These include not only severity at baseline, number of previous episodes and quality of study, which the draft guideline tried to address, but also sample size, age, sex, socio-economic 
factors, therapist factors, as well as treatment dose and administration of treatment, which the draft did not address.

The NMA included 351 studies comparing 81 interventions and combinations of interventions, which differed considerably in all these variables, thus violating the transitivity or consistency assumption ${ }^{16}$. The variable distribution and thus contribution of the different treatments included in the NMA is highly problematic. It is evident that some treatments contributed very few studies (e.g. yoga and any AD contributed only two studies), whilst others (e.g. individual CBT contributed 35 and Amitriptyline contributed 43 studies). Thus, findings might not depict a representative range of treatment, thereby biasing an effect estimate compared with those with more studies ${ }^{17}$.

It is our position, and in line with Canadian Agency for Drugs and Technologies in Health ${ }^{18}$, that findings from indirect or mixed comparisons (NMA) should only be used to supplement evidence derived from direct comparisons (standard meta-analysis). The evidence must be re-analysed accordingly. Given that the recommendations for first episode depression rely on these analyses, this will have a significant impact on the recommendations.

\section{The guideline must take proper account of non-symptom outcomes}

The current draft guideline has an extremely narrow focus on symptom outcomes and fails to take into account other aspects of service user experience which have long been called for, such as quality of life, relationships and ability to participate in work, education or society. The guideline scope lists adaptive functioning, carer wellbeing and a range of other outcomes among the list of main outcomes to be considered, and yet the guideline takes no account of these outcomes.

Analysis of these outcomes would significantly impact the findings of the reviews. This is known because a re-analysis of the 2004 NICE guideline studies focusing on non-symptom outcomes (quality of life and functioning) found that the 'best' treatments were not the same as those deemed 'best' from the analysis of symptom outcomes ${ }^{19}$. This re-analysis demonstrates that such a review is both possible and useful. The Guideline Committee state, without foundation, that such an analysis is not possible because of the limited number of studies reporting such outcomes. Large amounts of inadequate evidence should not be used in place of small amounts of good evidence. Service users express a preference for improvements in quality of life over symptom change. The principle of patient-centred care, enshrined in the NHS Constitution and other NHS policies, demands that NICE take account of what service users actually want from treatment. NICE must run a re-analysis of studies using quality of life and/or functioning outcomes where these are available and prioritise recommendations based on these measures, given that these are the measures of greatest priority to service users.

\section{Conclusion}

If these serious methodological flaws are not adequately addressed in the guideline, the treatment recommendations cannot be relied on and will be misleading, invalid and impede the care of millions of people in the UK, potentially causing clinical harm. During the meeting between this coalition of stakeholders and NICE, NICE representatives suggested that some of these concerns could be addressed in the next revision of the guideline. Whilst we hope that NICE will indeed improve their methodological approach in future guidelines, we maintain that these issues need to be addressed now and not postponed. NICE guidelines have a significant influence on UK policy as well as 
internationally and therefore, publishing this guideline in its current form would have a very damaging impact on service users, services, the health professional work-force and research practices.

${ }^{1}$ NICE (2014). Developing NICE guidelines: the manual

'Jobst, A., Brakemeier, E.L., Buchheim, A., Caspar, F., Cuijpers, P., Ebmeier, K.P... Padberg, F. (2016). European Psychiatric Association Guidance on psychotherapy in chronic depression across Europe. European Psychiatry, 33, 18-36.

${ }^{3}$ Leichsenring, F., Abbass, A., Hilsenroth, M.J., Leweke, F., Luyten, P., Keefe, J.R.... Steinert, C. (2017). Biases in research: risk factors for non-replicability in psychotherapy and pharmacotherapy research. Psychological Medicine, 47(6), 1000-1011.

${ }^{4}$ Health Foundation (2017). Healthy lives for healthy people.

SCochrane Collaboration (2011).

'Hepgul, N., King, S., Amarasinghe, M., Breen, G., Grant, N., Grey, N... Cleare, A.J.(2016). Clinical characteristics of patients assessed within an Improving Access to Psychological Therapies (IAPT) service: results from a naturalistic cohort study (Predicting Outcome following Psychological Therapy; PROMPT). BMC Psychiotry, $16(1), 52$.

${ }^{7}$ McPherson \& Priestley (2016). Couples Disease: the experience of living with a partner with chronic depression. Journal of Couple and Relationship Therapy, 17/ 2), 128-145.

"NICE (2014). Developing NICE guidelines: the manual, p107.

"Noyes, J., Popay, J., Pearson, A., Hannes, K. \& Booth, A. (2011). Qualitative research and Cochrane Reviews. In J. Higgins \& S. Green (Eds.), Cochrane Handbook for Systematic Reviews of Interventions (version 5.1.0) (chapter 20). The Cochrane Collaboration.

${ }^{10}$ Jobst, A., Brakemeier, E.L., Buchheim, A., Caspar, F., Cuijpers, P., Ebmeier, K.P... Padberg, F. (2016). European Psychiatric Association Guidance on psychotherapy in chronic depression across Europe. European Psychiatry, 33, 18-36.

"Hengartner, M. (2017). Methodological flaws, conflicts of interest and scientific fallacies: implications for the evaluation of antidepressants. Frontiers in Psychiotry, December 2017.

${ }^{12}$ Keefe, R. (2015). Correspondence. Heightened risk of false positives in a network meta-analysis of social anxiety. British Medical Journal, 2(4),292-293.

${ }^{15}$ Del Re, A.C., Spielmans, G.I., Flückiger, C. \& Wampold, B.E. (2013). Efficacy of new generation antidepressants: Differences seem illusory. PLOS ONE, 8(6), e63509.

${ }^{14}$ Kibret, T., Richer, D., and Beyene, J. (2014). Bias in identification of the best treatment in a Bayesian network meta-analysis for binary outcome: a simulation study. Clinical Epidemiology, 6, 4S1-60.

${ }^{15}$ Cipriani, A., Higgins, J., Geddes, J.R., and Salanti, G. (2013). Conceptual and technical challenges in network meta-analysis. Annals of Intermal Medicine, 159, 130-137.

${ }^{10}$ Baker, S.G. and Kramer, B.S. (2002). The transitive fallacy for randomized trials: if $A$ bests $B$ and $B$ bests $C$ in separate trials, is A better than C? BMC Medical Research Methodology, 2, 13.

"Keefe, R. Ibid.

${ }^{11}$ Wells, G.A., Sultan, S.A., Chen, L., Khan, M. and Coyle, D. (2009). Indirect Evidence: Indirect Treatment Comparisons in Meta-Analysis. Ottawa: Canadian Agency for Drugs and Technologies in Health.

${ }^{13}$ McPherson, S., Evans, C. \& Richardson, P. (2009). The NICE Depression Guidelines and the recovery model: is there an evidence base for IAPT? Journal of Mental Health, 18(5), 405-414. 